Check for updates

Cite this: Chem. Commun., 2020, 56, 7147

Received 17th April 2020,

Accepted 19th May 2020

DOI: 10.1039/d0cc02788j

rsc.li/chemcomm

\section{Synthesis of multisubstituted cycloalkenes through carbomagnesiation of strained cycloalkynes $\dagger$}

\author{
Yuya Tamura, Yasunori Minami, (D) Yoshitake Nishiyama, (D) Yuki Sakata, \\ Fumika Karaki, (D) Takamitsu Hosoya (D) and Suguru Yoshida (D)*
}

\begin{abstract}
An efficient synthetic method of seven- and six-membered cycloalkenes through the generation of strained cycloalkynes and following carbomagnesiation is described. Further bond formations of the resulting cycloalkenylmagnesium intermediates with a wide variety of electrophiles enabled us to prepare diverse cycloalkene derivatives including benzoxepine analogs having a fully substituted alkene structure.
\end{abstract}

Medium-sized ring compounds are of great importance in broad research fields including pharmaceutical sciences and materials chemistry. In particular, constructing condensed medium-sized ring structures having a number of substituents is a significant and challenging issue in synthetic organic chemistry, as shown by the various bioactive arene-fused cycloheptane derivatives such as modulators for estrogen receptor (ER) (Fig. 1A). ${ }^{1-3}$ Despite the continuous efforts toward developing synthetic methodologies for condensed ring compounds, it is not easy to prepare multisubstituted fused cycloheptanes by conventional methods due to the limited cyclization methods forming a seven-membered structure. ${ }^{4}$ We herein describe an efficient method to synthesize multisubstituted cycloalkenes involving arene-fused cycloheptenes by carbomagnesiation of transiently generated strained cycloalkynes $^{5-7}$ and subsequent bond formation with a variety of electrophiles.

Transformations via the carbomagnesiation of alkynes catalyzed by transition-metals such as copper and iron have been employed in tetrasubstituted alkene synthesis (Fig. 1B). ${ }^{8}$ Keeping in mind the versatility of carbomagnesiation and difficulty of cyclization to form seven-membered rings, we envisioned that a wide range of multisubstituted cycloheptenes can be prepared by the carbomagnesiation of transiently generated cycloheptynes followed by further bond formations with

Laboratory of Chemical Bioscience, Institute of Biomaterials and Bioengineering, Tokyo Medical and Dental University (TMDU), 2-3-10 Kanda-Surugadai,

Chiyoda-ku, Tokyo 101-0062, Japan. E-mail: s-yoshida.cb@tmd.ac.jp

$\dagger$ Electronic supplementary information (ESI) available: Experimental procedures and characterization for new compounds including NMR spectra. See DOI: 10.1039/d0cc02788j

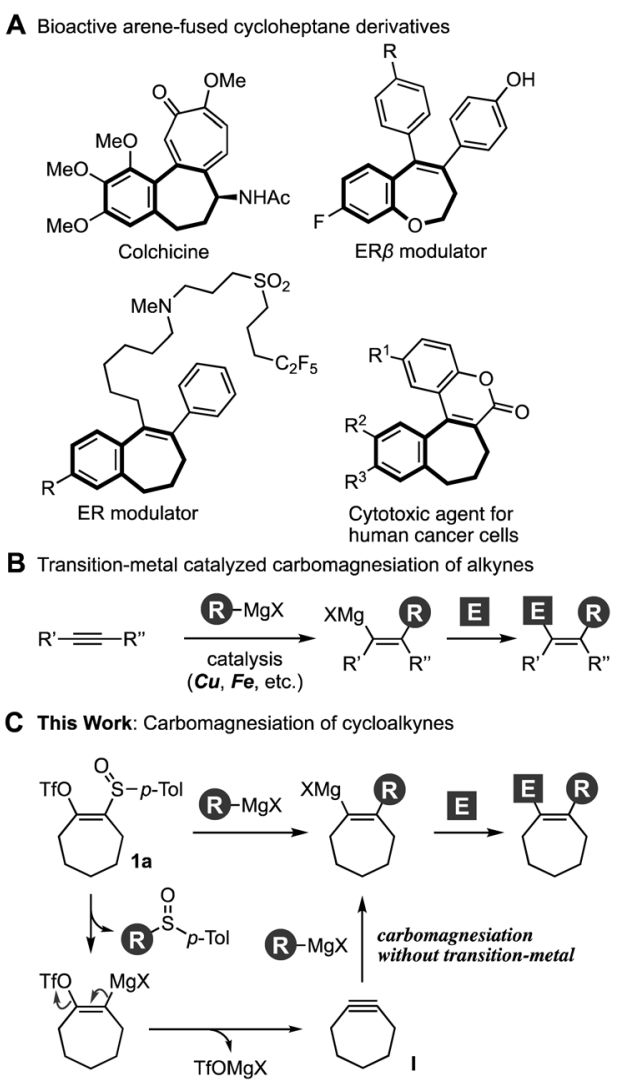

Fig. 1 Background and design of this study. (A) Bioactive arene-fused cycloheptane derivatives. (B) Catalytic carbomagnesiation of alkynes. (C) Concept of this work.

electrophiles on the basis of our recent achievements (Fig. 1C). Previously, we have developed an efficient cycloheptyne generation method from 2-(p-tolylsulfinyl)cycloheptenyl triflate (1a) using a phenyl Grignard reagent through sulfoxide-magnesium exchange ${ }^{9}$ followed by $\beta$-elimination, enabling us to prepare a variety of cycloheptene derivatives by cycloaddition with ynophiles including azides. ${ }^{7}$ The cycloalkyne generation method 
from easily accessible precursors and potential electrophilicity of angle-strained cycloalkynes ${ }^{6 a, h-j, 10}$ motivated us to develop cycloalkene synthesis through the carbomagnesiation of cycloalkynes, which is a challenging issue due to the less polar $\mathrm{C}-\mathrm{C}$ triple bond and the similar nucleophilicity of the resulting alkenylmagnesium intermediates.

Considering the significance of arene-fused cycloheptene scaffolds, we first attempted the carbomagnesiation of benzenefused cycloheptyne II from sulfoxide $\mathbf{1 b}$ with phenylmagnesium bromide at room temperature (Fig. 2A). After quenching with aqueous ammonium chloride, benzene-fused cycloheptene 2a was obtained in high yield as a single isomer, where the regioisomer $2 \mathbf{a}^{\prime}$ was not detected. ${ }^{11}$ This result clearly showed that the phenyl Grignard reagent acted both as an activator to generate cycloheptyne intermediate II and as a nucleophile to form cycloheptenylmagnesium intermediate III. As no catalysts or harsh conditions were required, this transformation was promoted by the inherent reactivity of transient intermediate II with a distorted alkyne configuration.

A broad range of Grignard reagents participated in the seven- and six-membered cycloalkyne generation and following carbomagnesiation (Fig. 2B). Indeed, benzene-fused cyclohep-

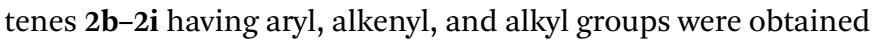
in moderate to good yields with the simple procedure only by adding the corresponding Grignard reagents at room temperature without any transition-metal catalysis (Fig. 2C). Aryl Grignard reagents bearing an electron-donating or electron-withdrawing substituent at the $p$ - or sterically hindered $o$-position also facilitated cycloalkyne generation and subsequent regioselective carbomagnesiation, affording benzene-fused cycloheptenes $\mathbf{2 b - 2 e}$ after protonation. In addition, benzene-fused cycloheptenes $\mathbf{2 f}-\mathbf{2} \mathbf{i}$ were also prepared using vinylmagnesium bromide and primary and secondary alkyl Grignard reagents in moderate yields.

Diverse seven- and six-membered cycloalkenes were successfully synthesized by the cycloalkyne generation and carbomagnesiation sequence (Fig. 2D). For example, treatment of benzoxepine-type cycloalkyne precursors, prepared easily from the corresponding ketones, with phenylmagnesium bromide followed by protonation selectively provided various benzoxepine derivatives 3-5 in high yields without damaging the methoxy and bromo groups. It is worth noting that the carbomagnesiation product 6 was prepared in good yield from the corresponding 2-sulfinylcycloalkenyl triflate without alkene isomerization. The reaction of a thiophene-fused cycloheptyne also proceeded smoothly to afford cycloheptene 7 in moderate yield. Furthermore, we succeeded in the generation of benzene-fused cyclohexynes and following carbomagnesiation to furnish 8-10 in low to high yields. In addition, phenylation of cyclohexyne also took place to provide 1-phenylcyclohexene (11) in moderate yield. When cycloheptyne precursor 1a was treated with a p-anisyl Grignard reagent, the following protonation afforded cycloheptene $\mathbf{1 2}$ in moderate yield along with a small amount of diene $\mathbf{1 3}$ as a byproduct formed by the reaction between alkenylmagnesium intermediate IV and cycloheptyne (I) (Fig. 2E). These results clearly showed that a wide range of cycloalkenylmagnesium intermediates can be prepared from various cycloalkyne precursors and Grignard reagents.

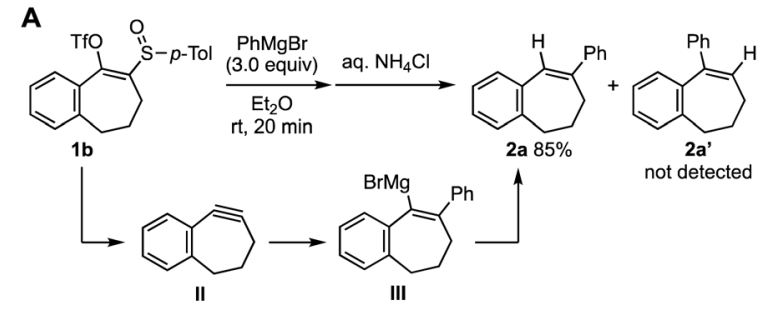

B

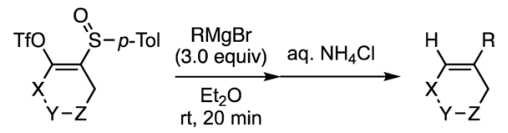

C<smiles>COc1ccc(C2=Cc3ccccc3CCC2)cc1</smiles><smiles>Clc1ccc(C2=Cc3ccccc3CCC2)cc1</smiles><smiles>COc1ccccc1C1=Cc2ccccc2CCC1</smiles><smiles>CC(C)c1ccccc1C=Cc1ccccc1Cl</smiles><smiles>[124In]</smiles>

2d $87 \%$<smiles>C=CC1=Cc2ccccc2CC1</smiles><smiles>CC/C=C\c1ccccc1[18OH]</smiles>

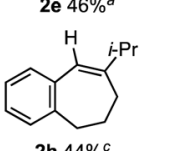<smiles>C1=C(C2CCCC2)CCCc2ccccc21</smiles><smiles>CC(C)c1ccccc1</smiles>
$386 \%$<smiles>Pc1ccccc1</smiles>

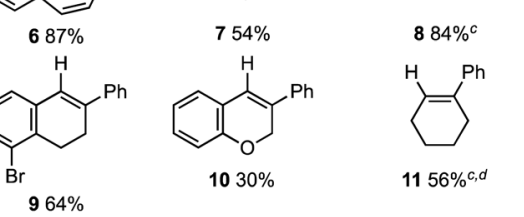

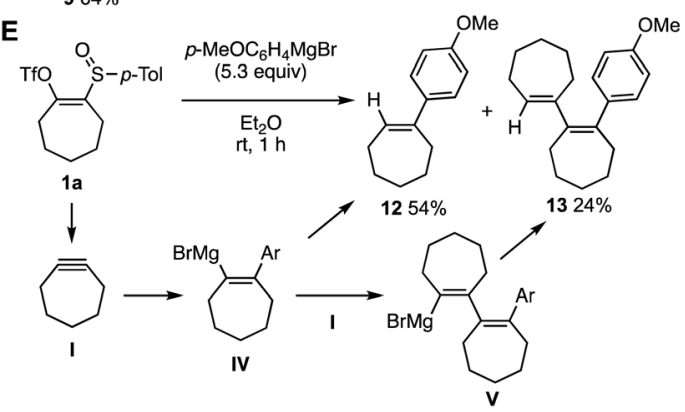

Fig. 2 Carbomagnesiation of in situ generated cycloalkynes. (A) Initial attempt. (B) General scheme. (C) Scope of Grignard reagents. (D) Scope of cycloalkynes. (E) Carbomagnesiation of cycloheptyne. ${ }^{a} 6.0$ equiv. of RMgX was used. ${ }^{b} 10$ equiv. of RMgX was used. ${ }^{c} 5.0$ equiv. of RMgX was used. ${ }^{d} \mathrm{THF}$ was used instead of $\mathrm{Et}_{2} \mathrm{O}$ as a solvent. See the ESI $\dagger$ for details.

Further bond-formations of the cycloheptenylmagnesium intermediate with a wide variety of electrophiles enabled the selective preparation of benzene-fused cycloheptenes $2 \mathbf{j}-\mathbf{2 r}$ containing fully substituted alkene scaffolds (Fig. 3). Indeed, an intermediate formed from $\mathbf{1 b}$ by the treatment with a phenyl 

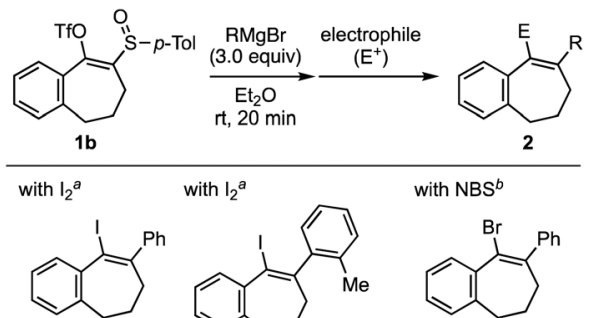

with $\mathrm{I}_{2}{ }^{\mathrm{a}}$

ith NBS ${ }^{b}$
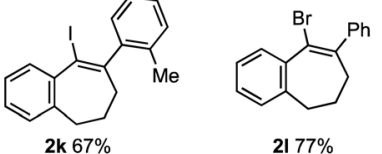

2j $89 \%$
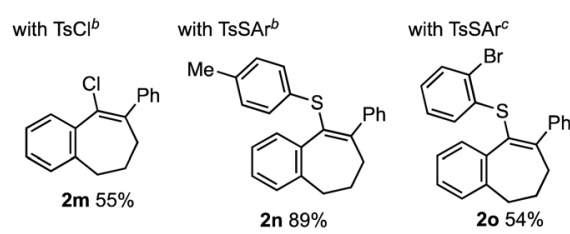

with $\mathrm{CO}_{2}$ (1 atm)

with $\mathrm{DMF}^{b}$
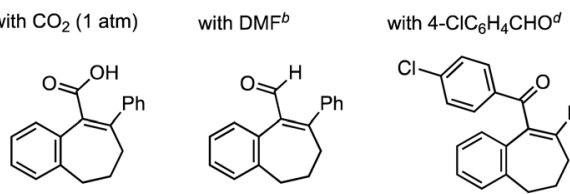

2p $67 \%$

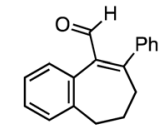

2q $49 \%$

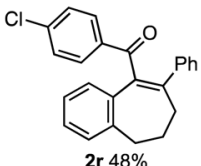

Fig. 3 Direct synthesis of disubstituted benzene-fused cycloheptenes ${ }^{a} 4.0$ equiv. of electrophile was used. ${ }^{b} 8.0$ equiv. of electrophile was used. ${ }^{c} 10$ equiv. of electrophile was used. ${ }^{d} 5.0$ equiv. of electrophile was used.

Grignard reagent was efficiently trapped with iodine to provide iodoalkene $2 \mathbf{j}$ in high yield. The efficiency of iodination was slightly decreased when using bulky $o$-tolylmagnesium bromide in the first step. Bromination and chlorination were also accomplished by trapping $N$-bromosuccinimide (NBS) and $p$-toluenesulfonyl (Ts) chloride ${ }^{12}$ to form bromide $2 \mathbf{l}$ and chloride $2 \mathrm{~m}$, respectively. Sulfanylation using thiosulfonates ${ }^{13}$ took place smoothly affording alkenyl sulfides $\mathbf{2 n}$ and $\mathbf{2 0}$ in good yields. Successful C-C bond formations with a variety of electrophiles such as carbon dioxide, $N, N$-dimethylformamide (DMF), and $p$-chlorobenzaldehyde were achieved to furnish tetrasubstituted alkenes 2p-2r selectively. Of note, the reaction using an aldehyde only afforded ketone $2 \mathbf{r}$ probably due to the oxidation by excess aldehyde. ${ }^{14}$ These results clearly showed that transformations through cycloheptyne generation and carbomagnesiation enable the synthesis of cycloheptenes having a wide variety of functional groups, which are difficult to prepare by conventional methods, in a practical and simple way.

Accessible cycloalkenes were remarkably expanded by the palladium-catalyzed cross-coupling reactions (Fig. 4). ${ }^{15}$ For instance, the reaction between cycloheptyne precursor $\mathbf{1 b}$ and phenylmagnesium bromide followed by the palladium-catalyzed Kumada-Tamao-Corriu coupling occurred smoothly, affording tetrasubstituted alkene 2s (Fig. 4A). Furthermore, the MizorokiHeck reaction between iodoalkene $2 \mathbf{j}$ and ethyl acrylate successfully provided diene 2t in high yield (Fig. 5B, upper). Also, alkynylation of iodide $2 \mathbf{j}$ by Sonogashira coupling resulted in the synthesis of enyne $2 \mathbf{u}$ (Fig. 4B, lower). The transformation involving palladium-catalyzed coupling allowed for the facile preparation of a benzoxepin-type selective ER $\beta$ modulator analog 14 (Fig. 4C). Indeed, the synthesis of benzoxepine derivative 14
A<smiles>CCOS(=O)C1=C(O)c2ccccc2CCC1</smiles>
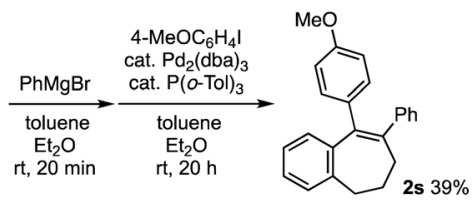

B
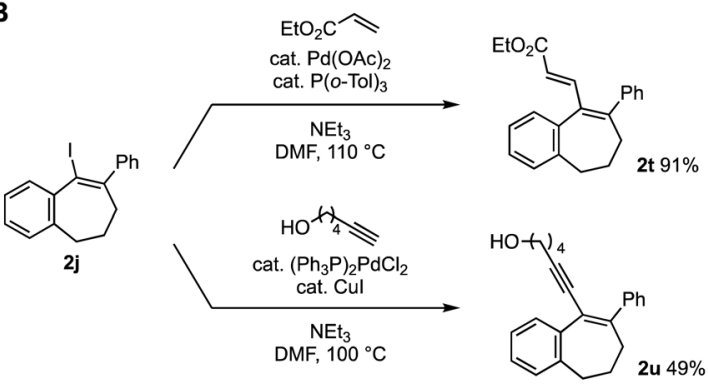

C
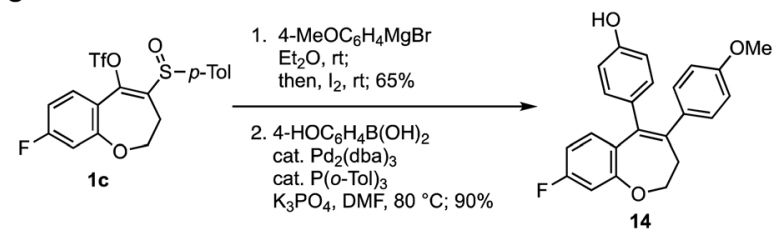

Fig. 4 Transformations involving catalytic $\mathrm{C}-\mathrm{C}$ bond formations. (A) Synthesis of $\mathbf{2 s}$. (B) Alkenylation and alkynylation of $\mathbf{2 j}$. (C) Synthesis of ER $\beta$ modulator analog 14. See the ESI† for details.

A

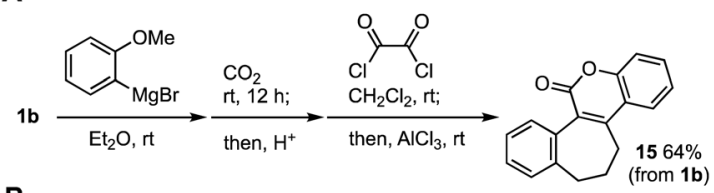

B

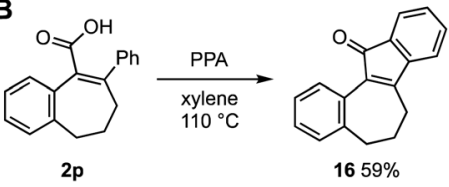

Fig. 5 Synthesis of analogs of a tetracyclic bioactive molecule. (A) Synthesis of 15. (B) Synthesis of $\mathbf{1 6}$. See the ESI $\dagger$ for details. PPA = polyphosphoric acid.

possessing fluoro, $p$-hydroxyphenyl, and $p$-anisyl groups was accomplished by carbomagnesiation of cycloalkyne generated from precursor 1c, followed by iodination and Suzuki-Miyaura cross-coupling, enabling the introduction of different aryl groups in a regioselective manner. Considering the introducible Grignard reagents and the versatility of cross-coupling chemistry, synthesizing not only the reported ER $\beta$ modulator through demethylation of the $p$-anisyl group but also diverse analogs will be realized only by changing the modules. ${ }^{1 b}$

The utility of cycloalkene synthesis via carbomagnesiation of cycloalkynes was showcased by preparing analogs of an anticancer tetracyclic compound (Fig. 5). We achieved the efficient synthesis of lactone 15 through $\boldsymbol{o}$-anisylation of benzene-fused cycloheptyne generated from precursor $\mathbf{1 b}$, followed by carboxylation with carbon dioxide and subsequent condensation, modifying the conditions for the preparation of cytotoxic 
compounds against cancer cells. ${ }^{3,16}$ Additionally, a deoxygenated analog 16 was synthesized by PPA-mediated cyclization of carboxylic acid 2p. Taking into account the difficulties to construct condensed skeletons containing a seven-membered ring and fully substituted alkenes, the present method using the convergent cycloalkene synthesis and further cyclization could enable developing bioactive compounds.

In conclusion, we have developed an efficient synthetic method of seven- and six-membered cycloalkenes through cycloalkyne generation, carbomagnesiation, and further bond formations with a wide variety of electrophiles. The carbomagnesiation of strained cycloalkynes disclosed the inherent reactivity of transiently generated cycloalkyne intermediates with a distorted alkyne configuration, which will remarkably expand the synthetic utility of cycloalkynes. Diverse arene-fused cycloheptene derivatives having a fully substituted alkene structure such as analogs of bioactive compounds were efficiently synthesized through this reaction. Further studies to examine the preparable cycloalkenes and expand the introducible nucleophiles instead of Grignard reagents based on the good electrophilicity of transiently generated cycloalkynes clarified in this study are now ongoing.

This work was supported by JSPS KAKENHI Grant Numbers JP19K05451 (C; S. Y.), JP18H02104 (B; T. H.), and JP18H04386 (Middle Molecular Strategy; T. H.); the Naito Foundation (S. Y.); the Japan Agency for Medical Research and Development (AMED) under Grant Number JP19am0101098 (Platform Project for Supporting Drug Discovery and Life Science Research, BINDS); and the Cooperative Research Project of Research Center for Biomedical Engineering.

\section{Conflicts of interest}

There are no conflicts to declare.

\section{Notes and references}

1 (a) I. Barrett, M. J. Meegan, R. B. Hughes, M. Carr, A. J. S. Knox, N. Artemenko, G. Golfis, D. M. Zisterer and D. G. Lloyd, Bioorg. Med. Chem., 2008, 16, 9554; (b) N. M. O'Boyle, I. Barrett, L. M. Greene, M. Carr, D. Fayne, B. Twamley, A. J. S. Knox, N. O. Keely, D. M. Zisterer and M. J. Meegan, J. Med. Chem., 2018, 61, 514.

2 (a) T. Wintermantel, C. Moeller, U. Bothe, R. Nubbemeyer, L. Zorn, D. Kosemund, A. Ter Laak, R. Bohlmann, L. Wortmann and D. Bierer, Bayer Pharma Aktiengesellschaft, WO2011161101, 2011; (b) T. Wintermantel, C. Moeller, U. Bothe, R. Nubbemeyer, L. Zorn, A. Ter Laak, R. Bohlmann and L. Wortmann, Bayer Intellectual Property GmbH, WO2013083568, 2013; (c) L. Zorn, D. Kosemund, C. Möller, H. Irlbaher, R. Nubbemeyer, A. Ter Laak and U. Bothe, Bayer Pharma Aktiengesellschaft, WO2015028409, 2015.

3 B. Yadagiri, U. D. Holagunda, R. Bantu, L. Nagarapu, C. G. Kumar, S. Pombala and B. Sridhar, Eur. J. Med. Chem., 2014, 79, 260.

4 For selected reviews, see: (a) J. O. Hoberg, Tetrahedron, 1998, 54, 12631; (b) T. V. Nguyen, J. M. Hartmann and D. Enders, Synthesis,
2013, 845; (c) K. T. de Oliveira, B. M. Servilha, L. C. Alves, A. L. Desiderá and T. J. Brocksom, in Studies in Natural Products Chemistry, ed. A. Rahman, Elsevier, Oxford, vol. 42, 2014, pp. 421-463; (d) Y. Hu, M. Bai, Y. Yang and Q. Zhou, Org. Chem. Front., 2017, 4, 2256.

5 For selected reviews, see: (a) R. W. Hoffmann, Dehydrobenzene and Cycloalkynes, Academic Press, New York, 1967; $(b)$ A. Krebs and J. Wilke, Topics Current Chemistry, 1983, vol. 109, 189; (c) H. Hopf and J. Grunenberg, in Strained Hydrocarbons, ed. H. Dodziuk, Wiley-VCH, Weinheim, 2009, ch. 7; (d) C. M. Gampe and E. M. Carreira, Angew. Chem., Int. Ed., 2012, 51, 3766.

6 For selected examples, see: (a) F. Scardiglia and J. D. Roberts, Tetrahedron, 1957, 1, 343; (b) G. Wittig and A. Krebs, Chem. Ber., 1961, 94, 3260; (c) F. G. Willey, Angew. Chem., Int. Ed. Engl., 1964, 3, 138; (d) W. Tochtermann, K. Oppenländer and U. Walter, Chem. Ber., 1964, 97, 1318; (e) W. Tochtermann, K. Oppenländer and U. Walter, Chem. Ber., 1964, 97, 1329; $(f)$ R. Breslow, L. J. Altman, A. Krebs, E. Mohacsi, I. Murata, R. A. Peterson and J. Posner, J. Am. Chem. Soc., 1965, 87, 1326; $(g)$ N. Atanes, S. Escudero, D. Pérez, E. Guitián and L. Castedo, Tetrahedron Lett., 1998, 39, 3039; (h) M. Fujita, Y. Sakanishi, M. Nishii and T. Okuyama, J. Org. Chem., 2002, 67, 8138; (i) C. M. Gampe and E. M. Carreira, Chem. - Eur. J., 2012, 18, 15761; $(j)$ J. M. Medina, T. C. McMahon, G. Jiménez-Osés, K. N. Houk and N. K. Garg, J. Am. Chem. Soc., 2014, 136, 14706; (k) S. F. Tlais and R. L. Danheiser, J. Am. Chem. Soc., 2014, 136, 15489; (l) T. K. Shah, J. M. Medina and N. K. Garg, J. Am. Chem. Soc., 2016, 138, 4948; $(m)$ Y. Hioki, K. Okano and A. Mori, Chem. Commun., 2017, 53, 2614; (n) J. V. Chari, F. M. Ippoliti and N. K. Garg, J. Org. Chem., 2019, 84, 3652; (o) Y. Hioki, T. Yukioka, K. Okano and A. Mori, Asian J. Org. Chem., 2018, 7, 1298; (p) E. R. Darzi, J. S. Barber and N. K. Garg, Angew. Chem., Int. Ed., 2019, 58, 9419; (q) R. Nakura, K. Inoue, K. Okano and A. Mori, Synthesis, 2019, 1561; (r) Y. Hioki, A. Mori and K. Okano, Tetrahedron, 2020, 76, 131103.

7 S. Yoshida, F. Karaki, K. Uchida and T. Hosoya, Chem. Commun., $2015,51,8745$.

8 For selected reviews, see: (a) K. Murakami and H. Yorimitsu, Beilstein J. Org. Chem., 2013, 9, 278; (b) D. S. Müllera and I. Marek, Chem. Soc. Rev., 2016, 45, 4552.

9 For selected examples, see: $(a)$ N. Furukawa, T. Shibutani and H. Fujihara, Tetrahedron Lett., 1987, 28, 2727; (b) L. Melzig, C. B. Rauhut, N. Naredi-Rainer and P. Knochel, Chem. - Eur. J., 2011, 17, 5362; (c) S. Yoshida, K. Uchida and T. Hosoya, Chem. Lett., 2014, 43, 116; (d) S. Yoshida, K. Uchida and T. Hosoya, Chem. Lett., 2015, 44, 691; (e) T. Kimura, H. Momochi, K. Moriuchi, T. Katagiri and T. Satoh, Tetrahedron Lett., 2017, 58, 3505.

10 J.-A. García-López and M. F. Greaney, Chem. Soc. Rev., 2016, 45, 6766.

11 Use of phenyllithium instead of phenylmagnesium bromide gave a complex mixture and phenylzinc bromide did not react with $\mathbf{1 b}$.

12 (a) F. Chemla, I. Marek and J.-F. Normant, Synlett, 1993, 665; (b) W. Lin, O. Baron and P. Knochel, Org. Lett., 2006, 8, 5673.

13 P. Mampuys, C. R. McElroy, J. H. Clark, R. V. A. Orru and B. U. W. Maes, Adv. Synth. Catal., 2020, 362, 3.

14 R. J. Kloetzing, A. Krasovskiy and P. Knochel, Chem. - Eur. J., 2007, 13, 215.

15 For recent reviews, see: (a) R. Chinchilla and C. Nájera, Chem. Soc. Rev., 2011, 40, 5084; (b) S. Jagtap, Catalysts, 2017, 7, 267; (c) M. M. Heravi, V. Zadsirjan, P. Hajiabbasi and H. Hamidi, Monatsh. Chem., 2019, 150, 535; (d) S. E. Hooshmand, B. Heidari, R. Sedghi and R. S. Varma, Green Chem., 2019, 21, 381.

16 When we attempted a reaction using 2-(p-tolylsulfinyl)-3,4-dihydronaphthalen-1-yl triflate with 2-naphthylmagnesium bromide followed by trapping with carbon dioxide, the corresponding carboxylic acid was not obtained. 